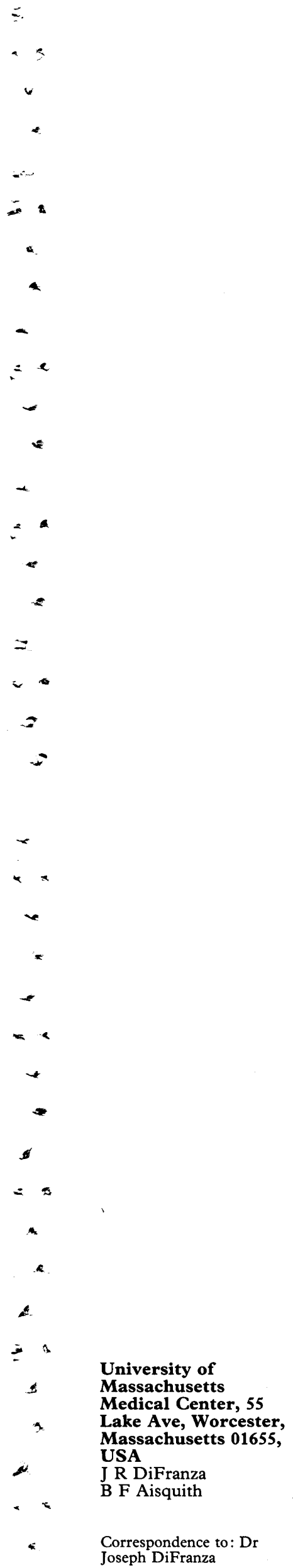

\title{
Does the Joe Camel campaign preferentially reach 18 to 24 year old adults?
}

Joseph R DiFranza, Bryan F Aisquith

\begin{abstract}
Objective - To determine if the Joe Camel advertising campaign is preferentially reaching 18 to 24 year olds as asserted by the RJ Reynolds Tobacco Company. Design - Cross sectional study conducted in 1994 comparing individuals who were 18-24 years old when the Joe Camel campaign was launched to those not in this target group.
\end{abstract}

Setting-Randomly selected public schools and community colleges in Massachusetts, USA.

Subjects-Public school students in grades 4 to 12 (ages 9-18), and community college students.

Main outcome measures - Recognition of Joe Camel, perceived prevalence of brand advertising, brand preference, age at first purchase of brand.

Results - The greatest familiarity with Joe Camel was shown by subjects who had been under the age of 18 at the launch of the campaign. Adults were much more familiar than children and adolescents with logos for other adult products, but not for Joe Camel. In comparison with advertisements for Marlboro and Newport cigarettes, Camel advertisements were identified by children of 10-13 years as those they had seen most often. About half the Camel smokers in the purported target group of 18 to 24 year olds had actually started buying Camels before they were 18. The majority of Marlboro and Newport smokers had also started with these brands when they were under age.

Conclusions-Although it is possible to advertise adult products preferentially to adults, this has not been the case with the Joe Camel campaign, which has had the greatest impact on individuals who were under 18 years of age at the launch of the campaign.

(Tobacco Control 1995; 4: 367-371)

Keywords: cigarette advertising; target age groups.

In 1988 the RJ Reynolds Tobacco Company introduced a new advertising campaign for its Camel brand featuring the Joe Camel cartoon character. Soon it was shown that Joe Camel rivalled Mickey Mouse for recognition by 6 year old children, and that 11 year old children noticed the advertisements more than individuals of any other age. ${ }^{1.2}$ Camel's share of the under age market had increased from $0.5 \%$ to $32.8 \%$ by 1991 , netting RJ Reynolds some $\$ 476$ million in illegal sales of Camel cigarettes to minors each year. ${ }^{3}$ Despite some variability, every survey of teenage brand preference conducted since 1989 has shown that the Camel brand is more popular among children than among adult smokers, a reversal of the situation before the introduction of Joe Camel. $^{3-5}$

Two years into the Joe Camel campaign it was found that children were more familiar than adults with the Joe Camel character. ${ }^{3}$ The inclusion of older adults (that is, those older than 24 years) in that study was criticised on the basis that RJ Reynolds subsequently claimed that their intention was to target individuals of 18 to 24 years of age ${ }^{6}$ Older adults were included because, before Joe Camel, Camels had been most popular among men over the age of $65 .^{7}$ Nevertheless, the data showed that Camel's market share was higher among smokers under the age of 18 than among 18 to 24 year old smokers (reanalysis of previously published data). ${ }^{3}$

In the light of RJ Reynolds' claim that the Joe Camel campaign was always targeted at 18 to 24 year olds, we sought to re-examine the issue. A simple comparison of those under age 18 and those in the 18 to 24 year old target group would no longer be valid, however. Anyone under 24 years of age when this study was conducted in 1994 would have been under 18 at the launch of the Joe Camel campaign. Given the impact that the Joe Camel campaign has had on children and teenagers, any success the campaign has had with individuals who are currently in the purported target group may be the result of exposure these individuals received when they were under $18 .^{1-3}$

Individuals aged 11-16 years in 1994 were 5-10 at the launch of the campaign (table 1). If the Joe Camel campaign is targeted exclusively at adults, it should have had demonstrably less effect on this group, many of whom could not read in 1988.

Individuals aged $17-23$ in 1994 were all under age (11-17 years) at the launch. Although most have since entered the target group, their exposure to the campaign as minors prevents their inclusion with those who were in the target group in 1988. The 17 year olds were not included with the younger subjects because many of the smokers in this 
Table 1 Age/sex distribution of subjects

\begin{tabular}{lcccc} 
& \multicolumn{4}{c}{ Age categories used in the data analysis } \\
\cline { 2 - 5 } & $A$ & $B$ & $C$ & $D$ \\
Age in 1988 (years) & $5-10$ & $11-17$ & $18-24$ & $>24$ \\
Age in 1994 & $11-16$ & $17-23$ & $24-30$ & $>30$ \\
\hline Males & 869 & 494 & 121 & 91 \\
Females & $873(50 \%)$ & $619(56 \%)$ & $181(60 \%)$ & $251(73 \%)$ \\
Total & 1742 & 1113 & 302 & 342 \\
\hline
\end{tabular}

group may have already chosen a regular brand when Joe Camel made his debut.

Individuals aged 24-30 years in 1994 were in the target group at the launch of the campaign and should theoretically be most familiar with Joe Camel and should have the highest proportion of Camel smokers.

Individuals over 30 in 1994 were already older than the target group at the launch of the Joe Camel campaign.

A primary concern of this study was a comparison of advertisement recognition between individuals who were in the target group at the launch of the campaign with those who were still under age.

As a measure of how effective various cigarette advertisements are at attracting the attention of individuals of different ages, subjects were asked which advertisements they had recently seen most frequently. If Joe Camel is targeted at 18 to 24 year olds, the highest responses for Camel should be seen among individuals who were currently in this age group.

Perhaps to suggest that Joe Camel is not recruiting more children to smoke, RJ Reynolds has claimed that $93 \%$ of Camel smokers aged 21 to 24 have switched from other brands. ${ }^{8}$ Conspicuous by their absence are data from the 18 to 20 year old smokers in RJ Reynolds' purported 18 to 24 year old target group. More importantly, though, the company does not reveal how old these individuals were when they switched to the Camel brand. While surveys suggest that the Joe Camel campaign is responsible for an increased prevalence of smoking among teenagers, ${ }^{9.10}$ from a legal standpoint it may be more important to determine if $\mathrm{RJ}$ Reynolds is soliciting illegal sales from minors in an attempt to improve its adult market share.

Cigarette brand preference is usually established very early, often with the first cigarette smoked. ${ }^{11}$ This suggests that RJ Reynolds' success in improving Camel's share of the 18-24 year old market may simply be the result of attracting under age smokers who stick with the brand as they grow older. To evaluate this possibility, young smokers were asked how old they were when they began to smoke their current brand. If the purpose of Joe Camel is to encourage 18 to 24 year old smokers to switch to the Camel brand, the vast majority of Camel smokers currently in this age group should have started smoking Camel after reaching the age of 18 .

One critic asserts that children are more familiar with "virtually all" advertisements than are adults, and therefore the fact that children are more familiar with Camel advertisements than are adults is not evidence that the campaign was targeted at youths. ${ }^{6}$ To test this assertion, children and adults were compared on their recognition of logos for two services that are purchased only by adults.

\section{Methods}

The subjects were students aged 11 years and older. Subjects were assigned to four categories according to their age at the launch of the Joe Camel advertising campaign (table 1). Power calculations identified a target of 1200 public school students and 1200 college students.

A community college, high school, junior high school, and grade school were recruited from each of four randomly selected communities. In Massachusetts, a typical student might attend grade school to age 12 , junior high to age 14 , high school to age 18 , followed by college. The names of all 13 Massachusetts state community colleges within a 100 mile $(161 \mathrm{~km})$ radius were drawn sequentially from a hat and the cooperation of the faculty at the first four schools was secured. The cooperation of the public school systems in the same communities was then obtained. Within each public school system, schools were selected by the school administration either at random or based upon logistical considerations.

To minimise selection bias in the public schools, all surveys were administered in classes that all students were required to attend. Likewise, in the colleges, surveys were administered in the required freshman English classes, but a variety of other classes had to be added to obtain a sufficient number of subjects in each age category.

A procedure for passive consent was approved by the Committee for the Protection of Human Subjects at the University of Massachusetts. The parents of the public school students were given the opportunity to withhold their children from the study. Less than one per cent chose to do so. Potential subjects were invited to participate in an anonymous study about advertising and all agreed to do so.

Anonymous self completed surveys were administered to the subjects in a classroom situation under examination conditions by a blinded research assistant. To discourage copying, alternating rows of students were given the same survey printed on different coloured papers. Students were advised not to copy because their neighbours might have different questions to answer.

The survey first asked for the subject's age and gender. A series of questions inquired about the subject's favourite brand of soft drink, cigarette, and magazine, and which brands of soft drink and cigarette they had seen the most advertisements for recently. Smokers were then asked to identify the brand of the last cigarette they smoked and the last cigarette they bought, and how old they were when they started smoking those brands.

Pilot testing of four logos for adult products was undertaken to identify two that were recognised by about half of the children and 


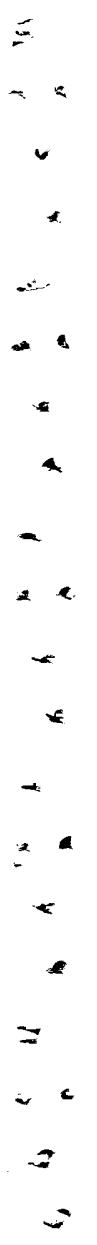

$-$

$<$

$-$

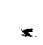

$-$

$\times$

$+$

a.

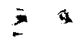

i adolescents. In this way, recognition of these logos by the adult respondents could fall above or below that of the youth groups. Adult recognition of these logos was not assessed at any time before the final study to eliminate any opportunity to bias the study. The logo for Bell Telephone was more recognised while that for $\mathrm{H} \& \mathrm{R}$ Block tax consultants was less recognised by the youngsters than were the two logos selected for the final study.

Subjects were then asked to identify, from projection slides, the American Airlines logo (an eagle with the initials "AA"), the word "Budget" from the Budget Rent-A-Car logo, and the Joe Camel cartoon character from which all smoking cues had been removed. Subjects were asked to identify the product and brand name associated with the Camel advertisement.

The completed surveys were entered into a database by the blinded research assistant. Data analysis was conducted using the $\chi^{2}$ test. A $p$ value of less than 0.05 was considered statistically significant.

\section{Results}

A total of 3600 subjects completed the survey. Table 1 presents the age and sex distribution, excluding 88 subjects who were under 10 years of age and 13 subjects for whom age or gender data were incomplete. Because of the increased proportion of females among the older students and gender differences in response to most of the survey items, gender stratified analyses were performed to control for gender bias.

Adults were much more adept than children and adolescents at identifying the advertisements for American Airlines and Budget RentA-Car. Among females, the American Airlines logo was correctly identified by $72 \%$ of adults 18 years of age or older, compared to $46 \%$ of the minors $(\mathrm{p}<0.001)$. For males, the results for adults and minors were $81 \%$ and $55 \%$, respectively $(\mathrm{p}<0.001)$. Among females, the Budget logo was correctly identified by $70 \%$ of the adults and $35 \%$ of the minors $(\mathrm{p}<0.001)$; among males, the results were $81 \%$ for the adults and $43 \%$ for the minors $(p<0.001)$.

By contrast, adults did not recognise Joe Camel better than minors (table 2). There were no significant differences in recognition rates between adults in the target group (category $\mathrm{C}$ ) and under age children (category

Table 2 Comparison of Camel advertising recognition rates (\%) among four age categories

\begin{tabular}{lcccc}
\hline & \multicolumn{4}{c}{ Age categories } \\
\cline { 2 - 5 } & $A$ & $B$ & $C$ & $D$ \\
Age in 1988 (years) & $5-10$ & $11-17$ & $18-24$ & $>24$ \\
Age in 1994 & $11-16$ & $17-23$ & $24-30$ & $>30$ \\
\hline Males & & & & \\
Identify product & $89^{\star}$ & $95 \dagger$ & $91^{\star}$ & 88 \\
$\quad$ Identify Camel brand & $81^{\star}$ & $91 \dagger$ & $86^{\star}$ & 85 \\
Females & $93^{\star}$ & $96+\ddagger$ & $92^{\star}$ & 88 \\
Identify product & $81^{\star}$ & $90 \dagger \ddagger$ & $81^{\star}$ & 83 \\
Identify Camel brand & & &
\end{tabular}

$\star p>0.05$ for comparison between categories $\mathrm{A}$ and $\mathrm{C}$.

$\dagger p<0.05$ for comparison between categories A and $B$

$\ddagger p<0.05$ for comparison between categories B and C.
A). Recognition rates were significantly higher in category B than in category A in all four comparisons. Recognition rates were significantly higher in category $\mathrm{B}$ than category $\mathrm{C}$ for both female comparisons.

Previous studies have revealed marked racial and ethnic differences in brand preference. ${ }^{4}$ One survey reported market shares for Newports among 12 to 18 year olds of $9 \%$ for whites, $34 \%$ for Hispanics, and $70 \%$ for blacks. Unanticipated differences in the racial and ethnic composition between the college and public school samples in this study rendered brand preference comparisons between age categories invalid. The proportion (per cent) of blacks and Hispanics in the public schools compared to the proportion in the college in each of the four communities was $43 / 9,34 / 10,16 / 13$, and $5 / 8$.

There were 736 smokers in our sample. Marlboro was the last brand smoked by $55 \%$ of smokers, followed by Newport $(25 \%)$, Camel $(3 \%)$, and 20 other brands. Gender differences in brand preference were apparent. The proportion of female smokers $(n=436)$ choosing Newport, Marlboro, or Camel was $30 \%, 48 \%$, and $1 \%$ respectively, whereas comparable values for male smokers $(n=299)$ were $17 \%, 64 \%$, and $5 \%$. There were no meaningful differences between the data for last brand smoked and last brand bought, so only the latter is discussed.

Of the Camel smokers over 17 years of age, $40 \%$ had started to smoke Camels before the to age of 18 , and of those who provided information, $50 \%(7 / 14)$ had first purchased Camels before they were 18. Six of the 13 Camel smokers $(46 \%)$ who were in the RJ Reynolds' purported target group of 18 to 24 year olds had started to smoke Camels before they were 18 .

Of the adult Marlboro smokers aged 18 and above, $70 \%$ had started smoking Marlboros, and $65 \%$ had first purchased Marlboros, before they were 18 . Similarly, $68 \%$ of adult Newport smokers had smoked Newports, and $62 \%$ had first purchased Newports, before the age of 18 .

The figure presents the data concerning the advertisements that are noticed most. The youngest subjects were most likely to respond with a specific brand. As would be expected on the basis of advertising expenditures, Marlboro was the most common response in all age categories. Only for Camel was the highest response among the youngest age group.

\section{Discussion}

This study shows that promotions for adult products do not have to appeal to youngsters. Young people do not recognise all advertisements better than adults. Logos for American Airlines and Budget Rent-A-Car were far more familiar to adults than to children and adolescents, despite being advertised on television.

In stark contrast, subjects who were in $\mathrm{RJ}$ Reynolds' purported target group of 18 to 24 year olds at the launch of the campaign did no better at identifying the Joe Camel character 
Male

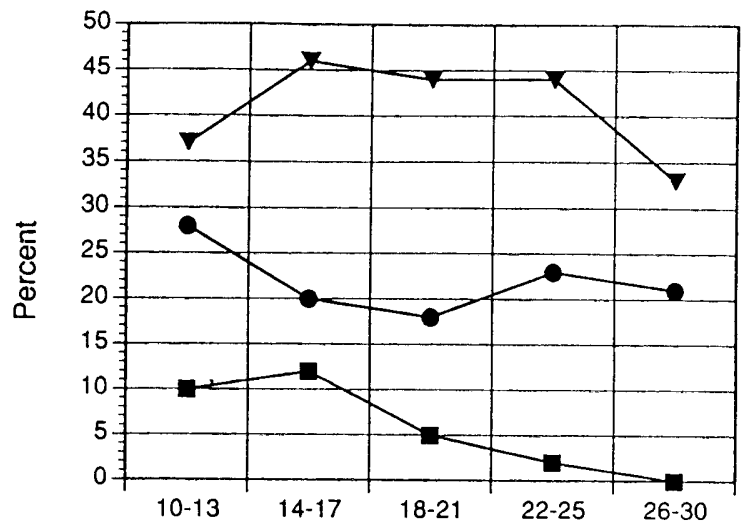

Age

Female

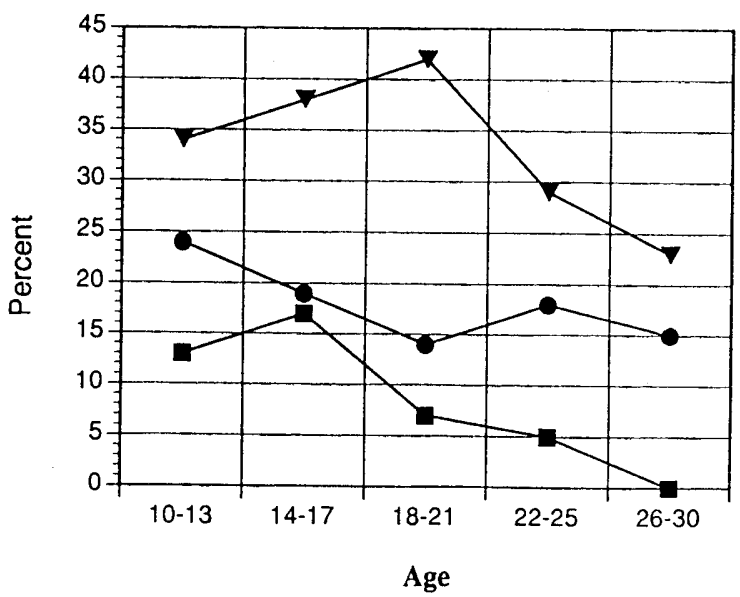

Percentage of subjects identifying each cigarette brand as the one they have seen the most advertisements for recently.
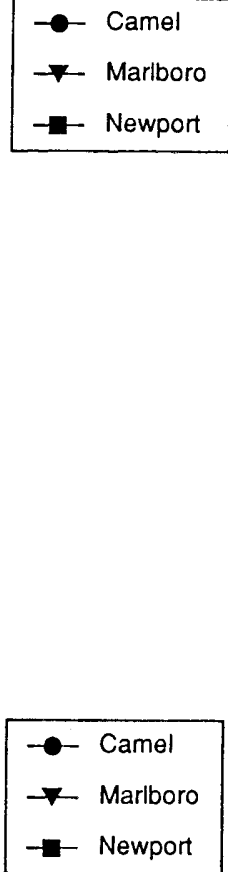

than did individuals who have been under age throughout the campaign. Indeed, the highest recognition rates for Joe Camel were among individuals who were aged 12-17 at the launch of the campaign.

In a previous study, Joe Camel was correctly identified by $94 \%$ of minors, but only $58 \%$ of adults, even though cigarettes cannot legally be advertised on television. ${ }^{3}$ Six years into the campaign, and following much controversy in the news, recognition of Joe Camel by adults appears to have increased but it still remains below that seen previously among under age subjects. The apparent decline in Joe Camel recognition rates among youths in this study may be an artefact due to the high proportion of minorities in our under age population.

Another approach to assessing the targets for an advertisement is to ask subjects of different ages to identify the cigarette brand they have seen advertised the most. ${ }^{2}$ The large discrepancies in promotional spending must be taken into account when making brand to brand comparisons. For example, promotional expenditures for the first nine months of 1993 were $\$ 61$ million for Marlboro, $\$ 32$ million for Camel, and $\$ 24$ million for Newport. ${ }^{12}$ That Camel's greatest success is in attracting the attention of the youngest children raises serious doubts about the claim that this campaign is targeted exclusively at adults.

Much of the success that RJ Reynolds has had in attracting its 18 to 24 year old target group is a result of its success at establishing Camel brand loyalty among under age smokers. Although this conclusion is based on a small sample of under age Camel smokers, the early establishment of brand preference is also reflected in our data concerning young adult Marlboro and Newport smokers, two thirds of whom had started smoking these brands when they were under age. This provides further evidence that teenage brand preference plays a key role in determining the initial distribution of adult brand preferences. ${ }^{11}$ In the battle over the $\$ 50$ billion US adult cigarette market, there is an enormous advantage to the company that best captures the children's market. This study found no evidence to contradict the assertion that Joe Camel represents RJ Reynolds' attempt to compete with Philip Morris (Marlboro) and Loews (Newport) for a share of the children's market segment.

One might look at table 2 and wonder if the high recognition rates among age category $\mathbf{B}$ is evidence that the campaign is currently preferentially reaching the 18 to 24 year old target group. This is unlikely. Given the historically higher Camel recognition rates among minors, ${ }^{3}$ the higher market share for Camel among under age smokers seen in several studies, ${ }^{3-5}$ and the fact that Camel advertisements have been most frequently noticed by relatively young children, ${ }^{2}$ the high recognition rates in category $B$ are most likely to reflect the exposure of these subjects to the Camel campaign when they were under age.

Sceptics may question the public health significance of a battle for the children's market segment: "One brand is as bad as another, so what difference does it make which brand youngsters are smoking?" Yet how can tobacco companies communicate to children who smoke that smoking their brand is an ultimately pleasurable experience without making smoking appear the least bit attractive to children who are actively contemplating it?

It is probably impossible for tobacco companies to fight to stimulate the demand for their individual brands among under age smokers without simultaneously stimulating children to use tobacco. While not addressed by this study, there is evidence that the promotion of tobacco products contributes to the initiation of tobacco use by youngsters..$^{3,13}$ A campaign for Regal cigarettes, which was remarkably similar to the Joe Camel campaign, was stopped after teenage smoking rates increased only in those regions of the United Kingdom where the campaign had run. ${ }^{14-16}$ Likewise, teenage smoking initiation rates in the United States have increased since the introduction of Joe Camel.9,10,17 While there may be no public health importance to which brand teenagers smoke, the increase in teenage smoking resulting from the battle over the children's market segment is a public health disaster. 
The use of a random sample of community colleges as a source of older subjects did not produce a population representative of the community. Confounding by racial and ethnic factors precluded a comparison of market shares among different age groups in this study. The low market share measured for Camel among youngsters in this study is likely to be due to the large minority representation. If young people are less likely to notice advertisements for brands not commonly smoked by their peers, the much higher proportion of ethnic and racial minorities among the adolescents compared to the adults in our sample would have worked against our hypothesis by lowering Camel recognition rates among our younger subjects. Racial and ethnic factors should be considered in planning future studies of youth brand preference. The results reported here should be confirmed in other populations.

This project was funded in part by a grant from the Massachusetts Tobacco Control Program. The authors wish to thank Robert Hilton, Ann Marie Iverson, Barbara Lamagna, Christopher Rowse, and the faculties of Bristol Community College, Massasoit Community College, Northern Essex Community College, Quinsigimond Community College, and the Brockton, Fall River, Haverhill, and Worcester public school systems for their contributions to this project.

1 Fischer PM, Schwartz MP, Richards JW, Goldstein AO, Rojas TH. Brand logo recognition by children aged 3 to 6 years. F $A M A$ 1991; 266 : 3145-8.

2 Pierce JP, Gilpin E, Burns DM, et al. Does tobacco advertising target young people to start smoking ? $\mathcal{J} A M A$ 1991; 266: 3154-8.

3 DiFranza JR, Richards JW, Paulman P, et al. RJR Nabisco's cartoon camel promotes Camel cigarettes to children. $₹ A M A$ 1991; 266: 3149-53.

4 US Centers for Disease Control. Changes in the cigarette brand preferences of adolescent smokers - United States, brand preferences of adolescent smokers

5 US Centers for Disease Control. Comparisons of the cigarette brand preferences of adult and teenaged smokers
- United States, 1989, and 10 US communities, 1988 and 1990. MMWR 1992; 41: 169-73, 179-81.

6 Dubow JS. A camel wronged. Food \& Beverage Marketing, February 1992: 13.

7 US Centers for Disease Control. Cigarette brand use among adult smokers - United States, 1986. MMWR 1990; 39 . 665-73.

8 Myerson AR. Selling cigarettes: who needs ads? New York Times, 3 March 1994: D1.

9 Pierce JP, Evans N, Farkas AJ, et al. Tobacco use in California : an evaluation of the Tobacco Control Program, 1989-1993. San Diego: University of California at San Diego, 1994.

10 Johnston LD, O'Malley PM, Bachman JG. National survey results on drug use from the monitoring the future study. Rockville, Maryland: US Department of Health and Rockville, Maryland: US Department of Health and 1994: 93. (NIH Publication No. 94-3809.)

11 DiFranza JR, Eddy JJ, Brown LF, Ryan JL, Bogojavlensky A. Tobacco acquisition and cigarette brand selection among youth. Tobacco Control $1994 ; 4$ : 334-8.

12 Brown K. Top 200 Megabrands by Jan-Sept ad spending. Advertising Age February 1994: 24

13 DiFranza JR The effects of tobacco advertising on children. In: Slama K, ed. Tobacco and health. New York: Plenum (in press).

14 Health Education Authority. An investigation of the appea and impact of the Embassy Regal "Reg" campaign on young and impact of the Embassy Regal "Reg" campaign on young

15 Hastings GB, Ryan H, Teer P, MacKintosh AM. Cigarette advertising and children's smoking: why Reg was advertising and children's smoking:

16 Chapman S. A requiem for Reg. Qualitative research can stop tobacco advertising that appeals to children. $B M Y$ $1994 ; 309: 890-1$

17 US Centers for Disease Control and Prevention. Trends in smoking initiation among adolescents and young adults United States, 1980-1989. MMWR 1995; 44: 521-5.
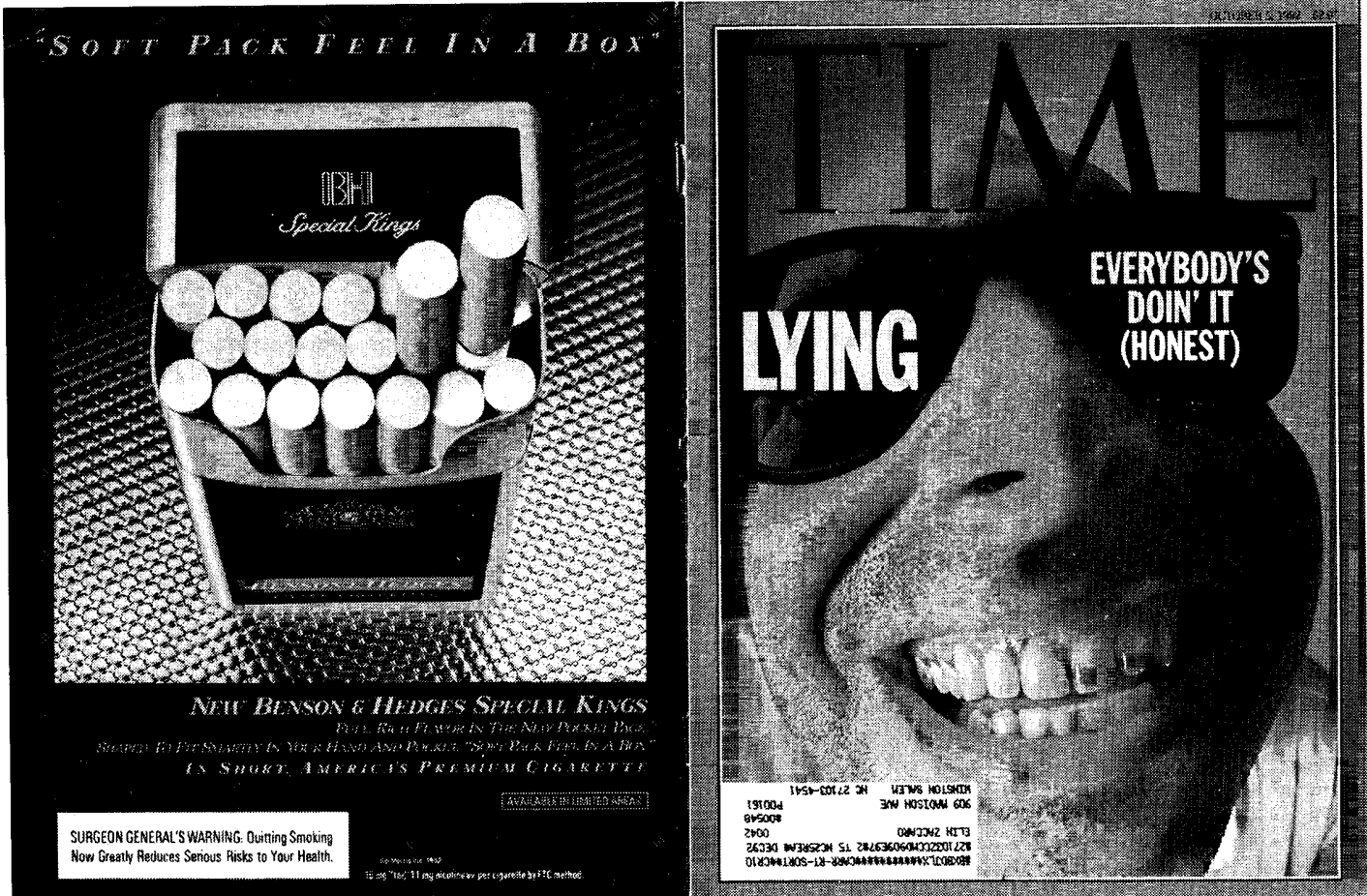

Submitted by Daniel J Zaccaro. 